International Journal of Engineering \& Technology, $7(2.7)(2018) 512-514$
International Journal of Engineering \& Technology
SPC
Website www.sciencepubco.com/index.php/IJET
Research Paper

\title{
Online Price Comparator and Reselling Website
}

\author{
Vemula Satyanarayana $^{1 *}$, Rahul Kumar Behera ${ }^{2 *}$, Gaurav Kumar ${ }^{3^{*}}$ \\ ${ }^{I}$ Department of electronics and computer engineering KLEF Deemed to be University \\ ${ }^{2}$ Department of electronics and computer engineering KLEF Deemed to be University \\ ${ }^{3}$ Asst Professor Department of electronics and computer engineering KLEF Deemed to be University \\ *Email: rahul.behera78@gmail.com
}

\begin{abstract}
World on online shopping is a present appraise in the beck of E-Business and is absolutely traveling to be the assured afterlife of shopping on the planet. Most of the associations are active their online passages to action their things/benefits online. Regardless of the way that web arcade is to a abundant amount accustomed alfresco India, its improvement in Indian Market, which is an immense and indispensable client feature, is still not as per the overall market. As there are numerous internet business sites accessible it ends up plainly troublesome for clients to pick best arrangement for wanted item among these sites. Examination of E-trade items utilizing web mining empowers clients to investigate costs and get wanted item at least cost.
\end{abstract}

Keywords: E-Business, Web Arcade, Internet Business, E-Trade, Web Mining

\section{Introduction}

On this present period of online business, internet business has turned into a big market for the general population to purchase merchandise web based. Increasing appliance of agog accessories and altered mediums has able for audience to acquirement items about from anyplace. This has expanded association of online purchasers advancing internet business. These huge quantities of web-based business sites place clients in turmoil to hunt and purchase a solitary item from different internet business sites. The proposed arrangement encourages online clients to get best arrangement for their item from numerous web-based business sites on single web interface. This will thus spare clients time, cash and endeavours to locate a similar item costs on various web-based business sites. Proposed framework utilizes web scratching procedure to remove information from web-based business site pages and furthermore web crawler to joins for items. It will empower customers to dismember costs and select things from same grouping for differentiating its features. This framework utilizes the accompanying innovations:

1. Web Crawler 2. Web Scrapper 3. MongoDB 4. Django Web Framework.

\section{Objective of research}

The essential target of the present investigation is to comprehend the internet purchasing conduct of customers in India. It has additionally made an endeavour to get data about the extent of change in internet shopping site. It gives a major picture of how India is rising in the field of web based business. The examination has coaxed conclusions out of the genuine information, which will give valuable data to the e-retailers to enhance their methodology towards web based shopping in India. Where we can able to buy a product at less price and also can check the prices of that product in different websites. Moreover, we can able to sell any product. Due to this we can have more benefit which is compression of product price and also selling through that website.

\section{Implementation}

Working of the anticipated framework is as per the following: The backend framework comprises of 2 imperative strategies web crawling and web rejecting. web rejecting could be a system that is acclimated remove data inside the human decipherable organization and show it on goal terminal. however, before rejecting the yield, web Crawlers zone unit responsible to explore to the goal once the crawler achieves the correct page and coordinates with the item, rejecting strategy begins. Crawler sporadically brings data from online business sites along these lines on check for refreshes. If refreshes zone unit available crawlers convey those updates and rolls out vital improvements inside the data.

\section{Analysis}

Now there are many different reasons why individuals are shopping from the web. For instance, customer will be able to do his/her shopping from anywhere or from any place without going to the shop; they can be able to locate a for all intents and purposes indistinguishable thing at a lower price by looking goals in the mean while; also they can keep up a key partition from in store auto immersion, and so forth. As indicated by our assumptions, these factors can be dense into four classes - comfort, information, available things and organizations, and cost and time capability.

1.Convenience 2.Information 3.Cost and time efficiency 4.Available products and services 


\section{Block Architecture}

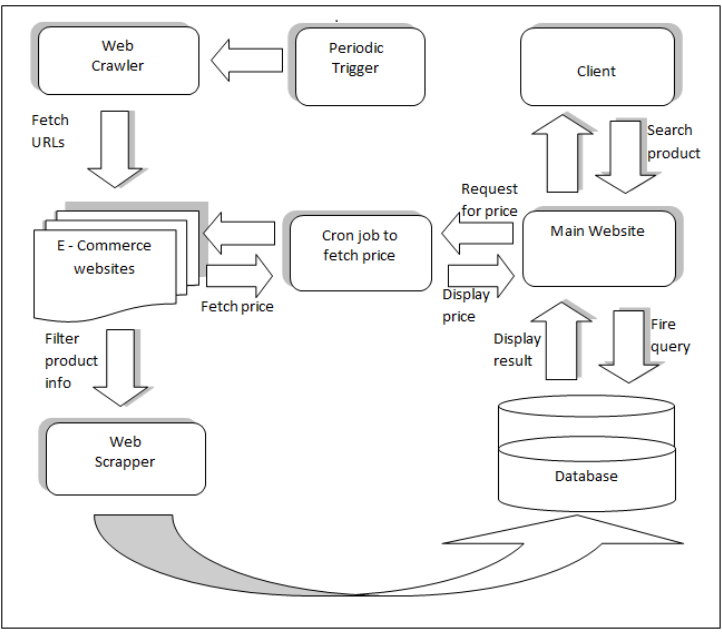

\section{Tools and Technologies}

Tool: Microsoft visual studio,

Technologies: HTML, PHP, CSS

Architecture: Visual Block Architecture

\section{System Testing}

The motive behind this testing is to get bungles. When two or more units are ready, they are assembled and Integration Then Testing is performed. When the complete website is integrated, System Testing is performed. The process of system testing is done to watch out whether it reaches or meets the specific need/requirement. This is the technique for practice code with the requirement of verifying that the Software framework lives up to its necessities related customer wants and doesn't flounder in an inadmissible way. There square measure various types of investigate. each investigate sort tends to a chose testing request.

\subsection{Types of Tests}

Here come the different types of testing which it requires to undergo these are:

\section{Unit testing 2. Integration testing 3. Functional test}

\section{Test Strategy and Approach:}

Where field testing can be done physically and helpful tests will be created in detail.

\subsection{Test objectives}

- Here field sections should work appropriately.

- Pages must be started from the recognized association.

- There should not be any delay for entry screen, messages and responses.

\subsection{Features to be tested}

- At first we require to verify weather the passages are on right format or not.

- There should not be any copy sections ought to be permitted.

- The connection should be able to take client to the correct page.

\subsection{Integration testing}

Programming combination testing is that the dynamic reconciliation testing of 2 or extra incorporated PC code parts on one stage to supply disappointments caused by interface surrenders.

\subsubsection{Test Results:}

Here all the test/experiment above passed successfully. No defects encountered.

\subsection{Acceptance Testing}

This is the type of testing which can be the sincere segment of any endeavor and needs essential interest by the best client. It conjointly identifies that the system meeting its supportive needs.

\subsubsection{Test Results:}

Here all the test/experiment above passed effectively. No imperfections experienced.

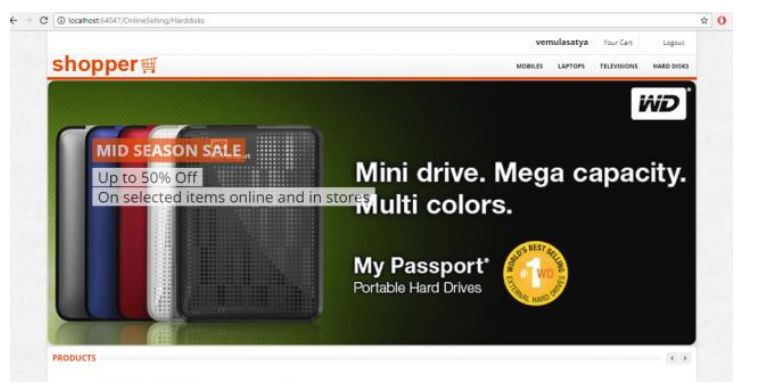

Fig 1: Index/Home page

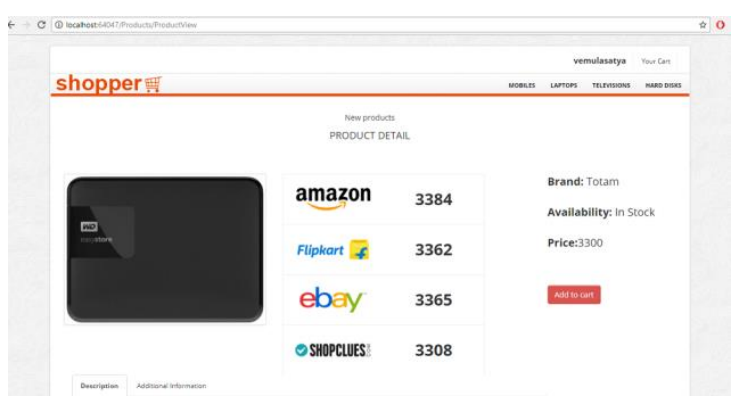

Fig 2: Price comparison page

\section{Result}

Correlation of item costs from various internet business sites and result is shown on single web interface. Likewise, framework enables client to investigate and think about item determinations for most extreme four items that lie under same class. To accomplish this outcome, the web mining is performed to bring the required item subtle elements and idea of web crawler and web scrubber is utilized to separate data of these items accessible on various web based business sites. Framework will enable clients to divert to unique site of that particular item chose by the client as a best arrangement. Following pictures demonstrate how item investigation and correlation of web based business locales is finished. The best thing is that we can ready to offer any item with your own cost. As a result by this website we can sell a product to a customer and customers can also be able to sell their own product by providing reselling page to the customers. Where they can able to post their used product with its detail and if any customer sees the post and wants to buy can contact with person who have posted. 


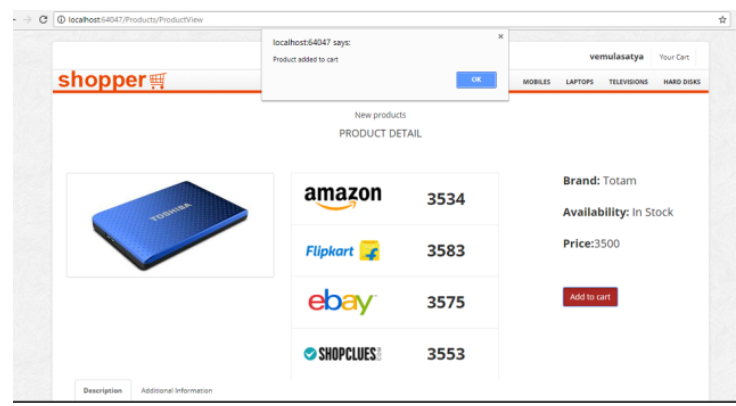

Fig 3: Price comparison page

\section{Conclusion}

Examination of E-business items utilizing web mining is electronic framework which will help clients in basic leadership while purchasing items on the web. This site will encourage clients to investigate costs that are available on various web based business shopping sites so they become more acquainted with the least expensive cost of item with best arrangement. The site will likewise have the office of contrasting items and every one of its details that have a place with same classification. This will without a doubt spare purchaser send favours and important time. At last, this will unite techniques, best offers and arrangements from all driving on the web stores and will help purchasers to shop on the web.

\section{References}

[1] Li Mei, Feng Cheng, "Overview of WEB Mining Technology and Its Application in Ecommerce", Proceedings of the 2010 IEEE 2nd International Conference on Computer Engineering and Technology, Vol. 7, 2010.

[2] Shridevi Swami, Pujashree Vidap ,"Web Scraping Framework based on Combining Tag and Value Similarity" Proceedings of the IJCSI International Journal of Computer Science Issues, Vol. 10, Issue 6, No 2, November 2013.

[3] Dr. Rajendra Nath, Khyati Chopra," Web Crawlers: Taxonomy, Issues \& Challenges" Proceedings of the International Journal of Advanced Research in Computer Science and Software Engineering, Volume 3, Issue 4, April 2013, pp. 944-948.

[4] Jos'e Ignacio Fern'andez-Villamor, Jacobo Blasco-Garc'ia, Carlos 'A. Iglesias, Mercedes Garijo "A Semantic Scrapping Model for Web Resources" Spain.

[5] Richard K. Lomotey, Ralph Deters," RSenter: Tool for Topics and Terms Extraction from Unstructured Data Debris", Proceeding of the IEEE International Congress on Big Data, 2013.

[6] I.Kali Pradeep, I. Bhagyasri, P. Praneetha," E-Commerce With Backbone Of Data Mining", Proceeding of the International Journal of Engineering Research \& Technology (IJERT), Vol. 2 Issue 7, July - 2013.

[7] Sastry, J.K.R., Naga Sai Tejasvi, T., Aparna, J., Dynamic scheduling of message flow within a distributed embedded system connected through a RS485 network, ARPN Journal of Engineering and Applied Sciences, Volume 12, Issue 9, 1 May 2017, Pages 2809-2817

[8] Sastry, J.K.R., Suresh, A., Bhanu, S.J., Building heterogeneous distributed embedded systems through rs485 communication protocol, ARPN Journal of Engineering and Applied Sciences, 2015, 10(16), pp. 6793-6803 